\title{
Contribució al coneixement de les algues epifítiques en llacunes litorals
}

\author{
JAUME CAMBRA
}

\begin{abstract}
Resum
Cambra, J. (1993). Contribució al coneixement de les algues epifítiques en llacunes litorals. Collect. Bot. (Barcelona) 22: 25-38.

Es presenten els resultats sobre les algues epifitiques d'hidròfits i helòfits en llacunes litorals. En general, les poblacions d'algues són força diversificades, destacant el grup de les diatomees, seguides de lluny per les cloroficies y les cianoficies.

En general totes les plantes aquàtiques es troben força epifitades. No obstant, les tiges de Phragmites australis presenten unes poblacions d'algues epifitiques molt importants, que es troben dominades per Cladophora glomerata v. crassior o Rhizoclonium riparium, acompanyades per un gran nombre d'espècies subordinades.
\end{abstract}

\begin{abstract}
Cambra, J. (1993). Contribution to the epiphytic algal in coastal lagoons. Collect. Bot. (Barcelona) 22: 25-38.

The results of a study on epiphytic algae in coastal lagoons are presented. Usually, the algal epiphytic assemblages on macrophytes are very diversified. The most important algal group are diatoms, with less abundance can appear green and blue-green algae.

The aquatic plants show a very rich epiphytic flora. However, the Phragmites australis stems are covered by dense populations of Cladophora glomerata v. crassior and Rhizoclonium riparium, as well as with a high number of subordinate species.
\end{abstract}

Keywords: epiphytic, algae, coastal lagoons, macrophytes, diatoms.

\section{INTRODUCCIÓ}

A les planes litorals de les nostres costes hi sovintegen les llacunes i els aiguamolls, generalment de poca fondària, amb aigües salabroses (amb l'ambigüitat $i$ amplitud que suposa utilitzar aquest terme) per barreja ocasional amb aigua marina, i fons fangosos. Aquests sistemes solen estar situats al desguàs de cursos d'aigua, amb freqüència braços fluvials abandonats, que en arribar al mar, topen amb dunes, barres sorrenques i altres materials sedimentaris que s'han acumulat a través dels anys. Una gran part de les llacunes són

J. CAmbra: Departament de Biologia vegetal. Facultat de Biologia. Universitat de Barcelona. 08028 Barcelona. 
alimentades per les aportacions d'aigua dolça que porta el riu o per aigües freàtiques. Sovint, el règim i el cabal de les aigües portades per les rierades o bé pels temporals d'aigua marina determinen les característiques i variacions de la físico-química de l'aigua. Altrament, les llacunes litorals poden tenir un origen exclusivament marí, per aïllament de masses d'aigua marina de poca fondària degut a la formació de barreres naturals. En aquest cas, les aigües presenten un grau de salinitat molt semblant al del mar i no tenen una variació dels caràcters físico-químics tan ampli com en el cas de les d'origen fluvial.

D'altra banda, a part dels factors ambientals, que produeixen una diversificació notable d'ambients, cal esmentar la important influència que té sobre aquests medis l'acció antròpica, ja que espontàniament hi hauria nombroses llacunes a les planes litorals, però l'home ha anat assecant aquestes terres per a destruir zones que considerava focus d'infecció, per guanyar terrenys de cultiu o amb finalitats exclusivament d'especulació.

Amb tots aquest condicionants generals, els diferents ambients costaners presenten comunitats vegetals també diverses, que depenen principalment de la concentració de sals dissoltes a l'aigua. No obstant, i amb la finalitat de sintetizar la diferent tipologia de poblaments vegetals aquàtics, només fem esment d'aquells que hem reconegut a les localitats estudiades.

A les llacunes hipersalines, a causa del desguàs d'aigües provinents de l'exportació industrial de sal, no s'hi desenvolupa cap hidròfit, ja que aquestes aigües tenen una excessiva concentració de clorurs. En medis amb menys contingut salí, però amb una marcada influència marina, solen desenvolupar-se herbassars de Ruppia (Ruppion maritimae $\mathrm{Br}$.-B1.), que esporàdicament poden reaparèixer en llacunes estepàries de l'interior. També en aigües salabroses, però amb aportacions periòdiques d'aigua dolça, s'hi estableixen poblaments formats per diversos potamogètons, Ceratophyllum demersum, ranuncles aquàtics $\mathrm{i}$ algunes caràcies. Aquesta diferenciació en el poblament vegetal que hem apuntat, pot trobar-se en una mateixa llacuna, ja que segons l'època de l'any, les aigües poden presentar un contingut de sals molt variable, com succeeix a les llacunes del delta de l'Ebre.

A les ribes, resseguint la línea litoral de les llacunes, els canyissars (Phragmition australis W. Koch) constitueixen un element comú del paisatge marjalenc.

Més lluny de l'aigua, les comunitats vegetals poden ser molt diverses i depenen principalment del tipus de substrat. En sòls sorrencs i dunes hi predominen espècies com la crucianel·la marina, timó marí, maçanella, escabiosa i jonc boval. En sòls salins s'hi estableixen comunitats d'halòfits, com ara les jonqueres halòfiles i els salicornars, que reapareixen també en llacunes de l'interior.

Tot i l'interès científic de les llacunes litorals, els estudis sobre les algues epifítiques d'aquests sistemes són pràcticament inexistents. Així doncs, seguint en la línia de recerca encaminada a investigar de forma sistemàtica les algues epifítiques dels nostres sistemes aquàtics (CAMBRA, 1987, 1990, 1991a,b), en aquesta comunicació s'aporten les primeres dades sobre aquest grup d'algues epibionts en llacunes litorals.

\section{AREA D'ESTUDI}

A la figura 1 s'observa la distribució de les localitats estudiades, que es situen entre els Aiguamolls de l'Empordà fins al cabo de Gata. A continuació es descriuen les principals característiques ecològiques de les llacunes estudiades: 


\section{1.- ALTAFULLA, Llacuna de (Tarragonès)}

Situada al desguàs del riu Gaià (31TCF6354), a nivell del mar i en direcció SE. Ocupa una superfície de 0,1 ha, aproximadament. Té poca fondària $i$ la seva forma és allargada, perpendicular a la costa.

Malgrat que es tracta d'una petita llacuna, el nivell de l'aigua es manté força constant durant tot l'any, encara que no descartem la possibilitat que en alguna ocasió es pugui assecar del tot. $(26 / 03 ; 22 / 04 ; 20 / 05 ; 28 / 06 ; 24 / 07 ; 20 / 09 / 1988)$

\section{2.- ENTINAS, Aiguamolls de las (Almería)}

Situats vora la població de Las Entinas (30SWF26). Hem recol-lectat material d'uns tolls de poca fondària i gran extensió, on es desenvolupaven masses importants d'algues filamentoses. $(9 / 04 / 1987)$

\section{3.- LLARGA, Llacuna de la (Alt Empordà)}

Situada al costat nord de la llacuna de la Massona, al desguàs del riu Fluvià (31TEG07), forma part dels aiguamolls de l'Empordà. (29/01/1987)

\section{4.- MASSONA, Llacuna de la (Alt Empordà)}

És la llacuna més meridional dels aiguamolls de l'Empordà, propera al desguàs del riu Fluvià (31TEG972), a nivell del mar i orientada en direcció WNW-SSE. Ocupa una superfície aproximada de 0,5 ha i és perpendicular a la costa.

En aquesta llacuna es produeix una quimioclina, ja que les aigües profundes tenen una concentració de sals més alta que les de superfície. Aquest efecte es produeix per la infiltració d'aigua marina del subsòl, que origina una llengua d'aigües marines al fons de la llacuna, mentre que les aigües superficials hi arriben provinents dels camps d'arròs de la rodalia.

No hem observat hidròfits, però en canvi, a les ribes, Phragmites australis forma un dens cinturó. (14/03; 20/04; 21/05; 26/06; 20/07; 17/09; 5/11/1988)

\section{5.- OLLES, Llacuna de les (Baix Ebre)}

Llacuna situada al braç nord del delta de l'Ebre (31TCF0618), a nivell del mar i en direcció SSW-NNE. Ocupa una superficie d'unes 10 ha i té una forma arrodonida.

A l'hivern, l'aigua és marina, ja que la llacuna es comunica amb el mar. No obstant, des de la primavera fins a les darreries de l'estiu, l'aigua de la llacuna es renova i esdevé dolça, ja que rep les aigües dels arrossars. En aquest període s'hi desenvolupen Ceratophyllum demersum, Lemna gibba i Potamogeton nodosus. A les ribes, Phragmites australis forma un important cinturó litoral. (26/03; 22/04; 20/05; 28/06; 24/07; 20/09/1988)

6.- REMOLAR, Estany del (Baix Llobregat)

Estany situat al delta del riu Llobregat (31TDF27), força alterat per a influència antròpica. (05/1982)

\section{7.- TANCADA, Llacuna de la (Montsià)}

Situada al braç sud del delta de l'Ebre (31TCF0901), a nivell del mar i amb una forma allargada, paral-lela a la costa. Com a les Olles, l'aigua presenta una alternança marina-dolça,ja que a aquesta llacuna hi arriba un canal que sempre comunica directament amb el mar i també rep les aigües drenades dels camps d'arròs propers, durant el període de conreu d'aquesta gramínia. 
A dins de l'aigua hi ha densos herbeis de Ruppia cirrhosa i principalment, Ruppia maritima, amb alguns claps de Potamogeton. (10/03/1987; 22/04; 20/05; 28/06; 24/07; 20/09/1988)

\section{METODOLOGÍA}

La recol-leció d'algues es realitzava mitjançant diversos raspats de la superfície dels hidròfits (tant fulles com tiges) i de les tiges dels helòfits. Tot aquest material així obtingut es depositava en flascons hermètics de $20 \mathrm{cc}$ i es fixaven amb formaldehíd al $4 \%$.

Paral-lelament a la recol-lecció d'algues, en cada campanya s'efectuaven mesures in situ dels següents paràmetres físico-químics: temperatura de l'aigua i oxigen dissolt (oxímetre WTW), $\mathrm{pH}$ (pH-metre CRISON) i conductivitat (conductímetre CRISON). A més, també es recollien $250 \mathrm{ml}$ d'aigua del litoral, que es fixava amb unes gotes de cloroform, per tal d'analitzar els clorurs i els sulfats, així com determinar l'alcalinitat.

Totes les mostres recollides es troben depositades a l'herbari d'algues del Dept. de Biologia Vegetal, Fac. Biologia, Univ. Barcelona sota la denominació BCC-JC.

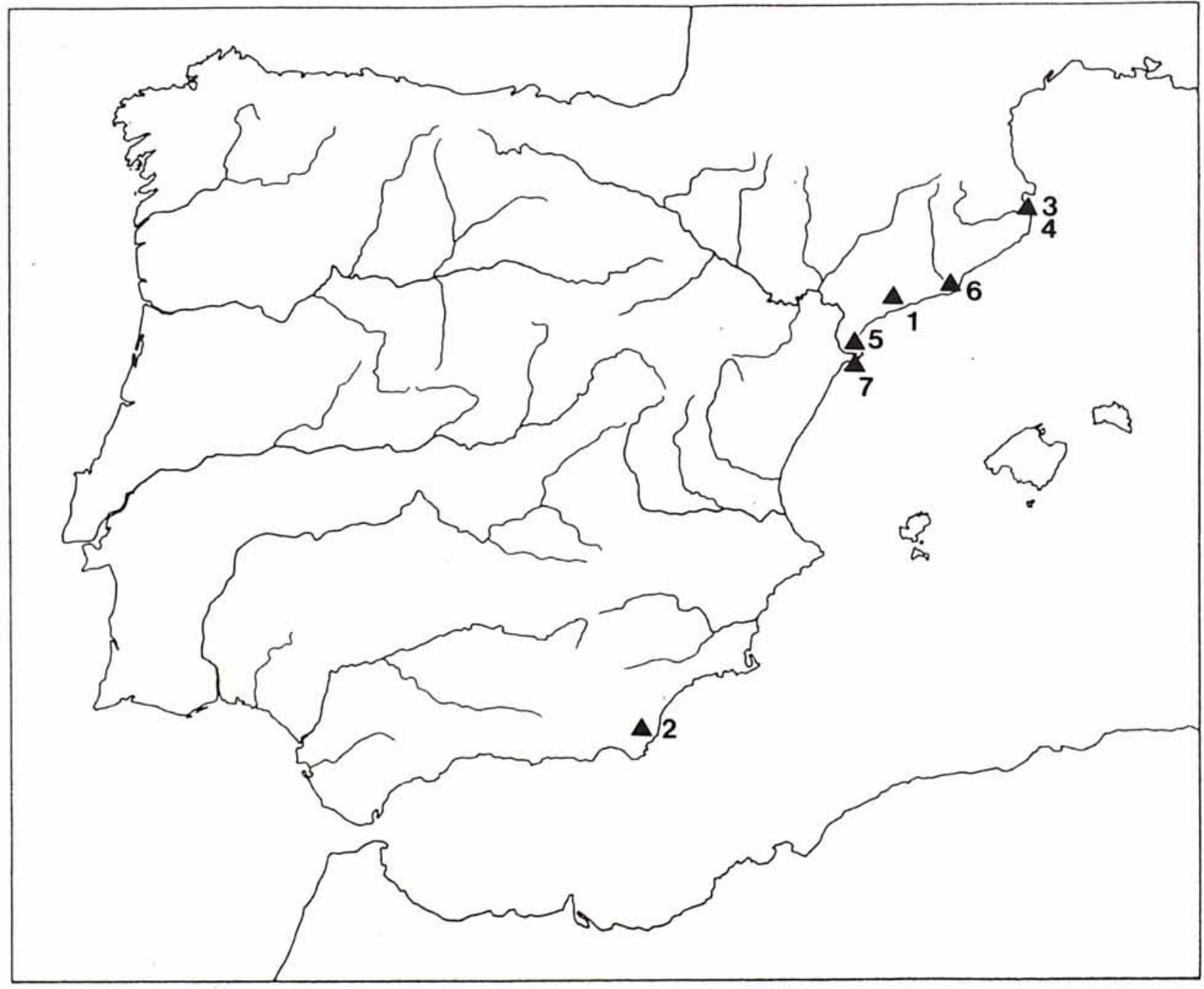

Fig. 1.-Situació geogràfica de les localitats estudiades. 1: Altafulla; 2: Entinas; 3: Llarga; 4: Massona; 5: Olles; 6: Remolar; 7: Tancada. 


\section{RESULTATS I DISCUSSIÓ}

Les llacunes costaneres presenten, en general, aigües molt mineralitzades. Les sals dissoltes provenen dels cursos dels rius propers i també del mar, al qual poden estar connectades de forma permanent o temporal.

Les aigües són força temperades i, en general, poc profundes. A més, com que estan situades vora la mar, la temperatura de l'aire no registra un descens important durant l'hivern, i aquest fet suavitza el clima. Els valors de temperatura de l'aigua també són suaus (Fig. 2) i varien entre $16.0-31.6^{\circ} \mathrm{C}\left(\mathrm{m} .=23.6^{\circ} \mathrm{C} ; \mathrm{d} . \mathrm{m} .=4.09^{\circ} \mathrm{C}\right)$, si bé, a l'hivern, els valors poden baixar a $3^{\circ} \mathrm{C}$ (COMIN, 1984).

L'alcalinitat és en general elevada (Fig. 3), amb valors entre $1.55-5.96 \mathrm{meq} / 1(\mathrm{~m} .=3.7$ $\mathrm{meq} / \mathrm{l}$; d.s. $=1.4 \mathrm{meq} / \mathrm{l})$. Aquest caràcter alcalí comporta una estabilitat relativa dels valors de pH (Fig. 4), que oscil.len entre 7.3-9.4 (m. =8.1; d.s.=0.6). No obstant, a finals de primavera i principis d'estiu, hem observat uns valors anormalment alts d'aquest paràmetre (9.2-9.4), que atribuïm a la intensa activitat fotosintètica de les algues i de les plantes aquàtiques, que es registra en aquesta època.

Pel que fa a la conductivitat (Fig. 5), els valors es mouen entre $951-19680 \mu \mathrm{S} / \mathrm{cm}$; d.s. = $6245.2 \mu \mathrm{S} / \mathrm{cm}$ ), xifres molt elevades si les comparem amb les dels estanys d'aigües dolces de l'interior (CAMBRA, 1991b). No obstant, aquest paràmetre presenta un comportament diferent en les llacunes estudiades. La variació annual de la conductivitat presenta uns valors màxims durant l'hivern i la primavera a les Olles, la Tancada i la Massona, per anar minvant a

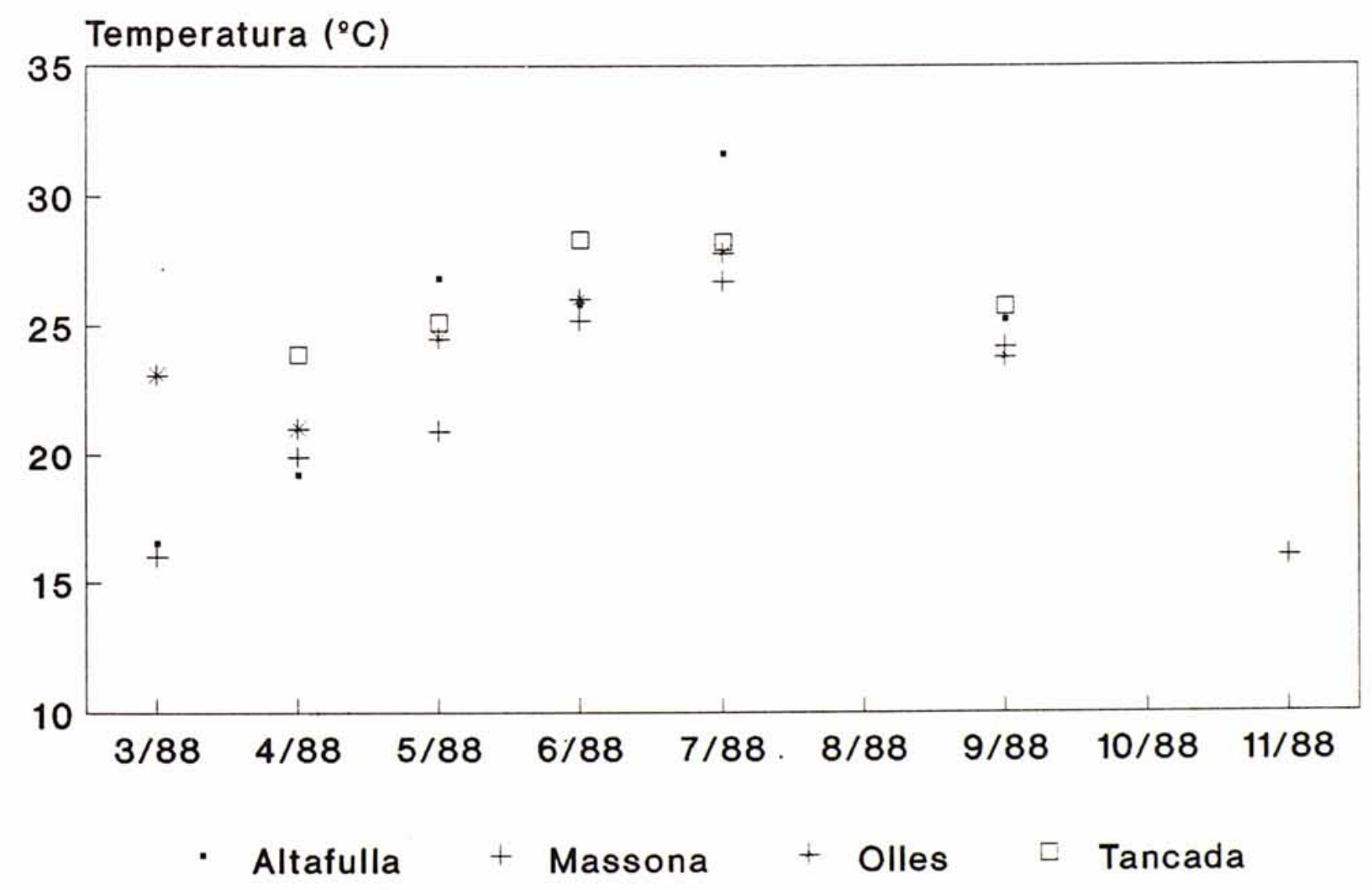

Fig. 2.-Variació de la temperatura $\left({ }^{\circ} \mathrm{C}\right)$ de l'aigua a les llacunes litorals. 


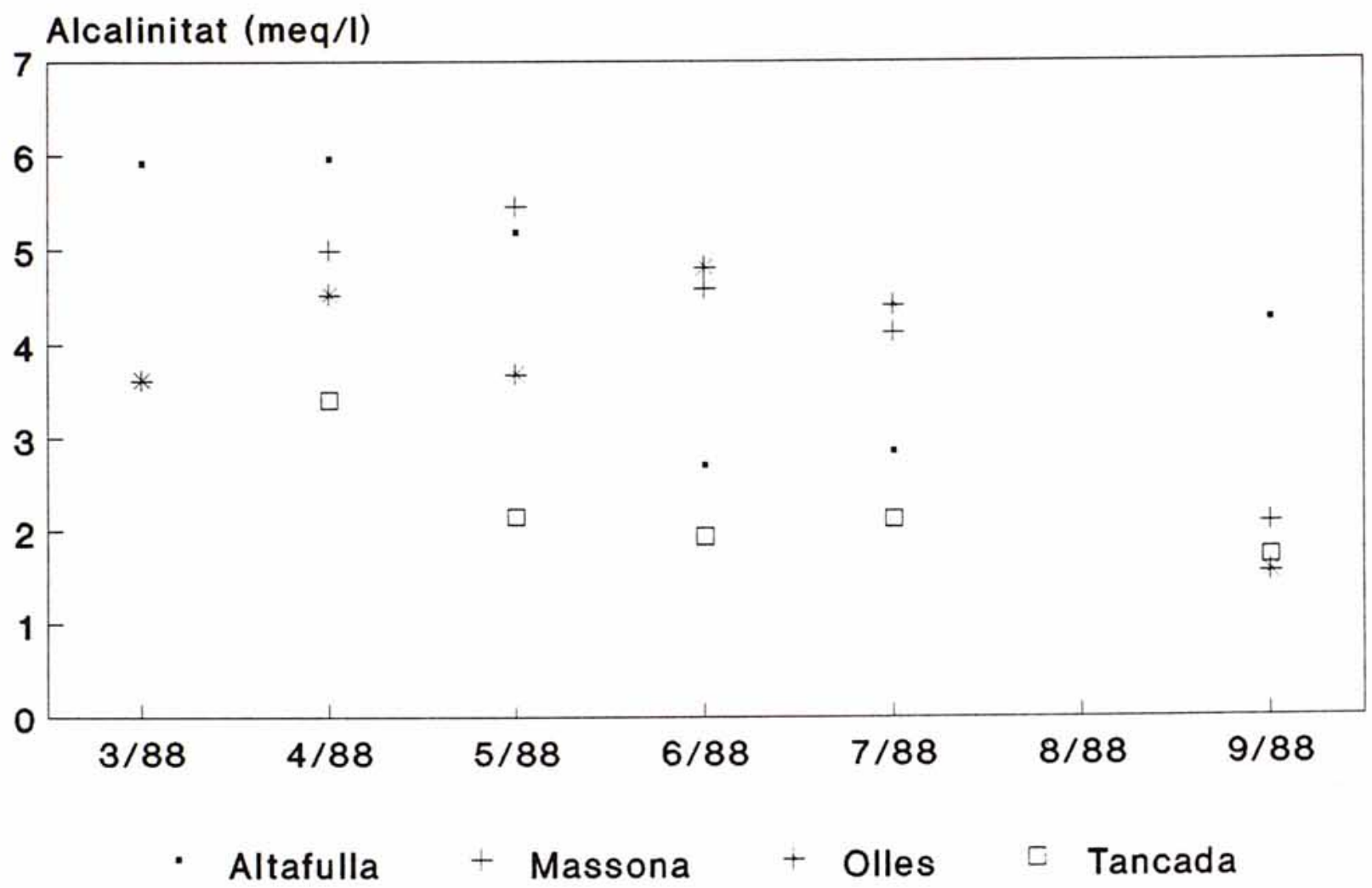

Fig. 3.-Variació de l'alcalinitat de l'aigua (meq.1-1) a les llacunes litorals.

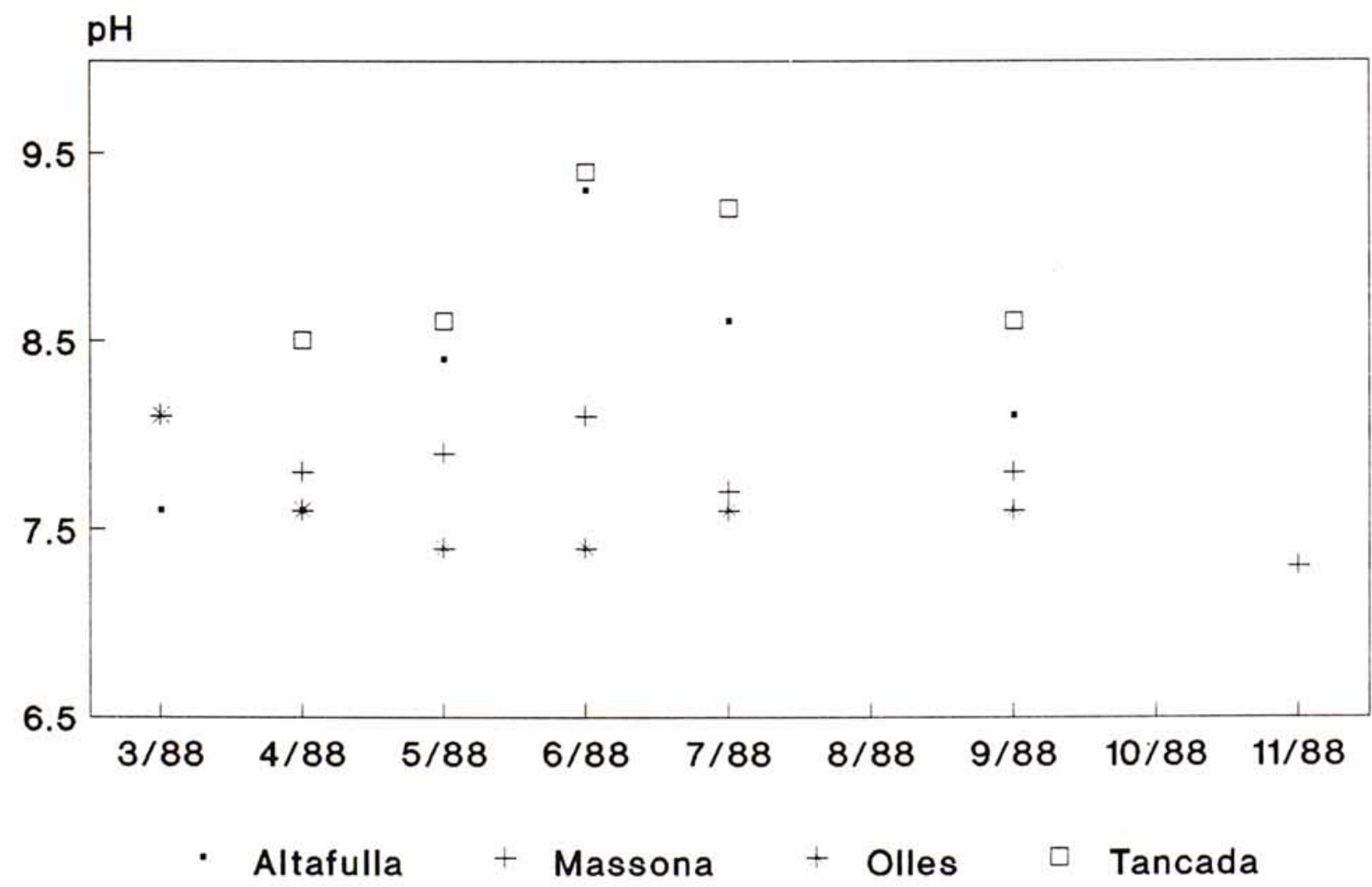

Fig. 4.-Variació del pH a les llacunes litorals. 


\section{Conductivitat $(\mathrm{mS} / \mathrm{cm})$}

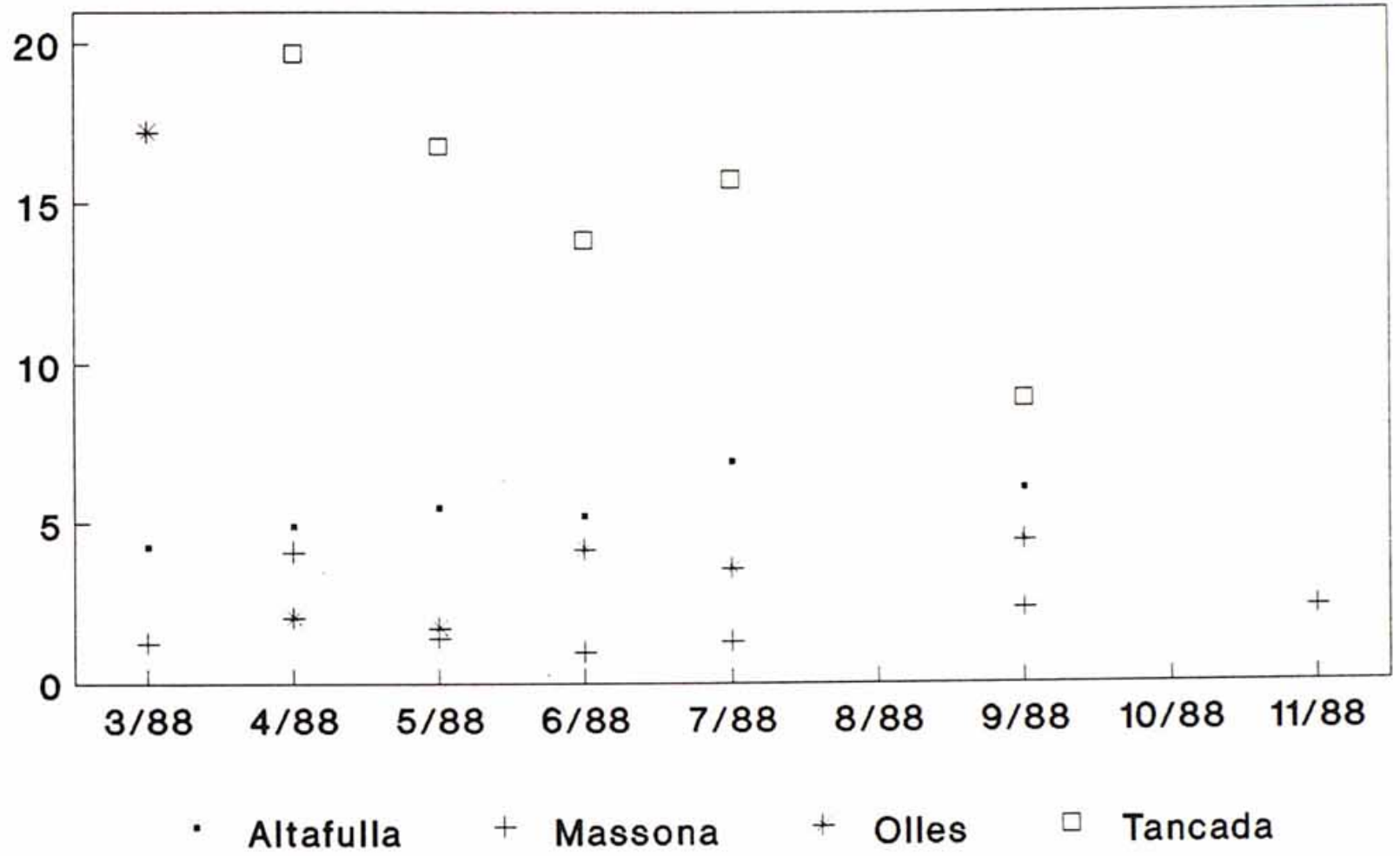

Fig. 5.-Variació de la conductivitat de l'aigua $\left(\mu \mathrm{S} . \mathrm{cm}^{-1}\right)$ a les llacunes litorals.

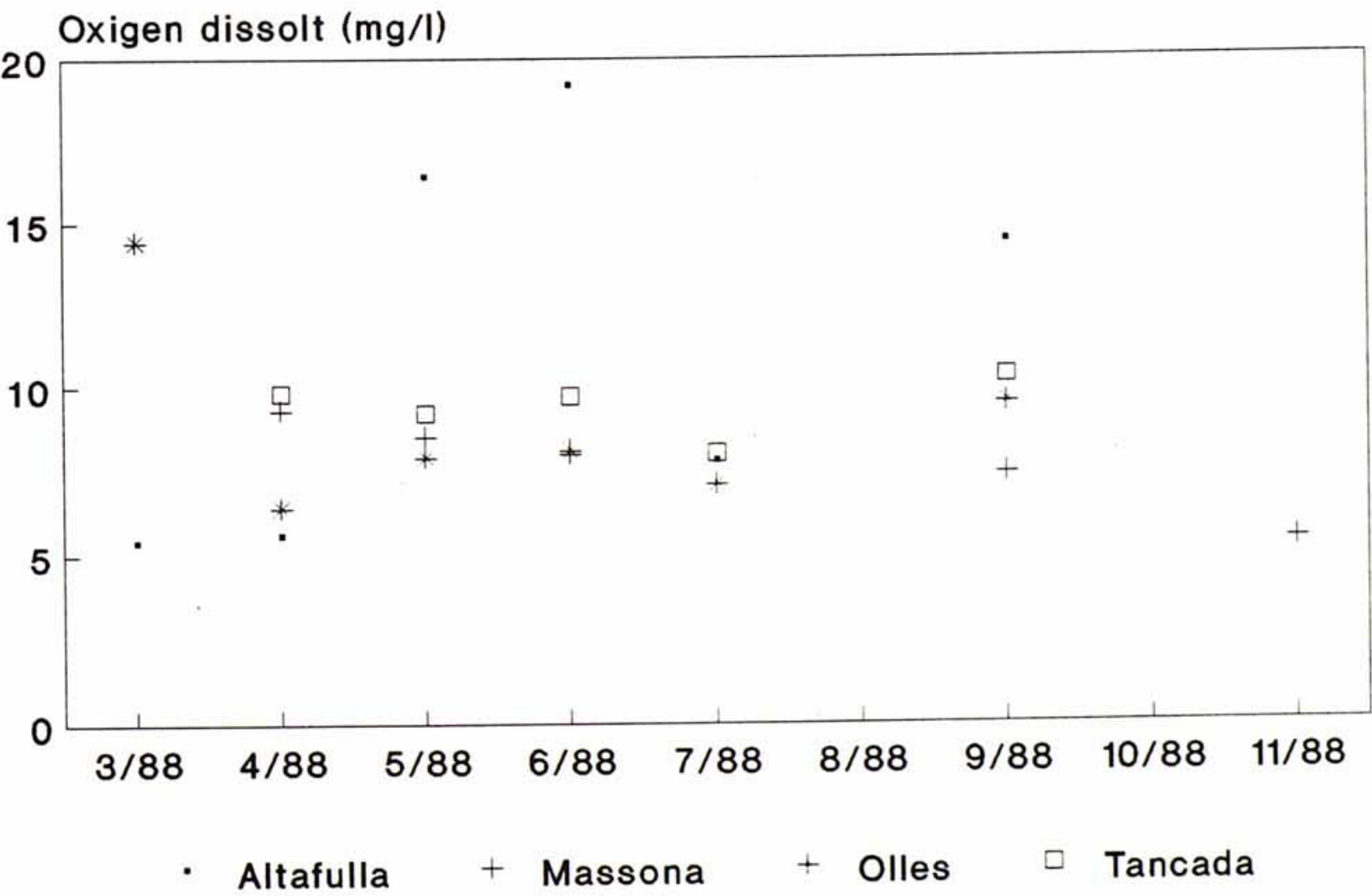

Fig. 6.-Variació de l'origen dissolt a l'aigua $\left(\mathrm{mg} .1^{-1}\right)$ a les llacunes litorals. 


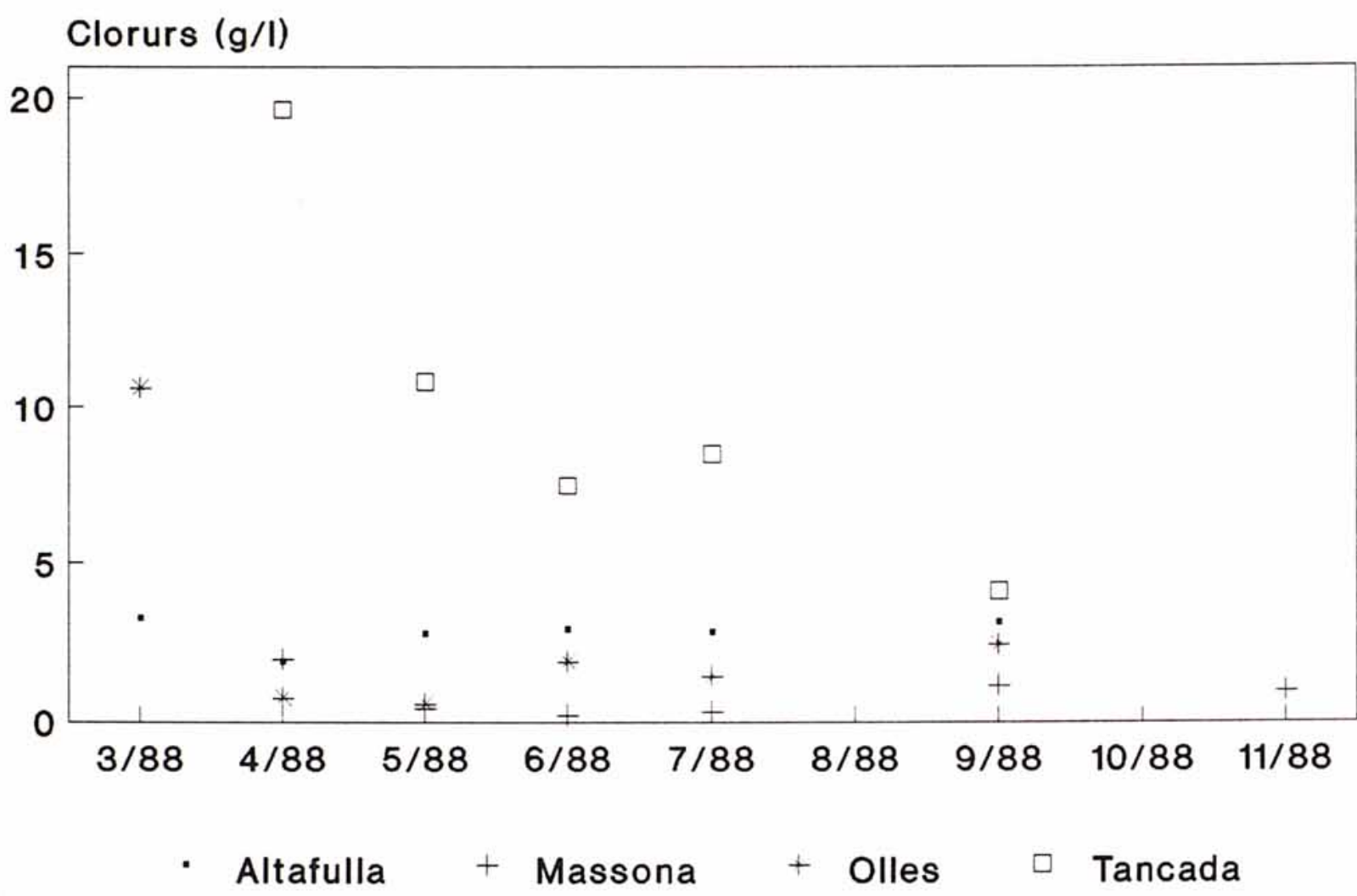

Fig. 7.-Variació dels clorurs (๑) dissolt a l'aigua (mg.1-1) a les llacunes litorals.

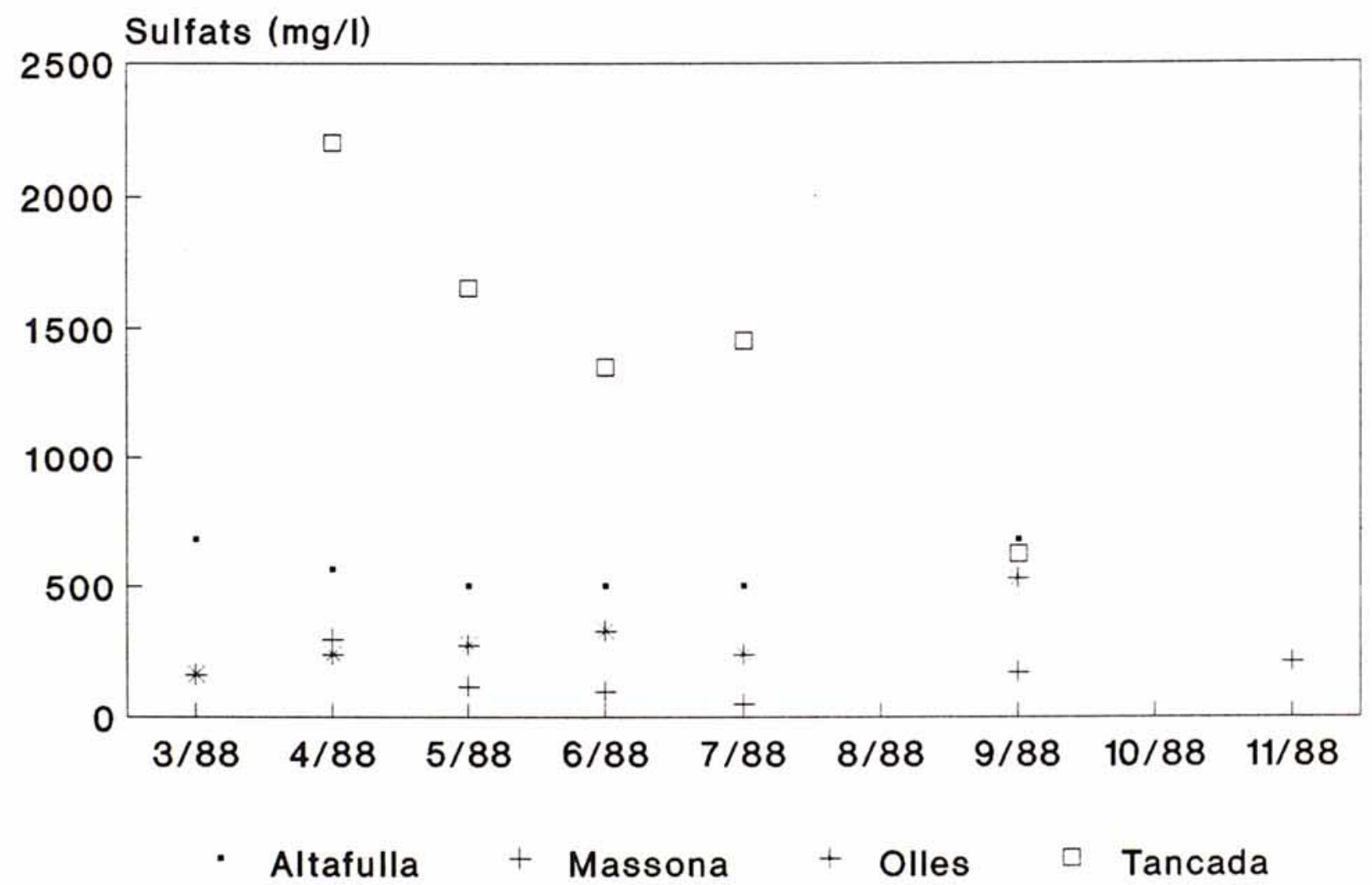

Fig. 8.-Variació dels sulfats dissolts a l'aigua (mg.1-1) a les llacunes litorals. 
mesura que avança l'estiu. A la llacuna d'Altafulla en canvi, observem un període amb conductivitats baixes a l'hivern i la primavera, així com un augment d'aquest paràmetre a l'estiu. Aquest cicle invers en el cas de les llacunes esmentades en primer lloc és produït pel cultiu d'arròs que circumda aquestes llacunes. L'aigua dolça dels arrossars, que és drenada pels canals de desguàs, va a parar a les llacunes. Això comporta un aport de nutrients i d'aigües dolces i, per tant, una disminució en la concentració de sals dissoltes, acompanyada per una reducció dels valors de la conductivitat. D'altra banda, a Altafulla, la forta evaporació de l'aigua a l'estiu fa incrementar la concentració de sals, fet que explica l'increment conseqüent de la conductivitat. En aquesta mateixa localitat però, es pot produir algun augment ocassional d'aquest paràmetre a l'hivern, principalment a causa dels tràngols que es produeixen en aquesta època.

L'oxigen també és força variable (Fig. 6), coincidint els valors màxims amb èpoques on la producció és elevada.

Com ja era de preveure, els valors de la concentració de clorurs són els més alts que hem registrat (Fig. 7), i oscil.len entre $300-19600 \mathrm{mg} / 1$ (m. $=4025.5 \mathrm{mg} / \mathrm{l}$; d.s. $=4706.7 \mathrm{mg} / \mathrm{l})$. La llacuna de la Tancada és la que presenta una concentració més elevada d'aquests anions (4100-19600 mg/l), i la de la Massona la que conté menys clorurs $(200 / 1930 \mathrm{mg} / \mathrm{l})$. No obstant, s'ha d'indicar que en aquesta darrera llacuna hi ha una quimioclina, amb una llengua d'aigua salabrosa a la part superior i aigües molt salines en fondària (ARMENGOL et al., 1984; RIERA et al., 1987). Així mateix, les concentracions de sulfats (Fig. 8) també són força elevades i es mouen entre $48-2200 \mathrm{mg} / \mathrm{l}(\mathrm{m} .=600.4 \mathrm{mg} / \mathrm{l}$; d.s. $=564.5 \mathrm{mg} / \mathrm{l})$.

En conjunt, veiem que a les llacunes costaneres es produeixen, en el decurs de l'any, unes variacions importants de la concentració de sals dissoltes, especialment pel que fa als clorurs. Això comporta que els organismes d'aquests sistemes han de presentar una regulació osmòtica suficient per a sobreviure a les diferents condicions ecològiques. Així doncs, a les llacunes costaneres es produeixen sovint successions relativament ràpides d'organismes, les poblacions dels quals venen afavorides o perjudicades segons les fluctuacions de la concentració de sals del medi. Aquestes variacions determinen uns models que ocorren de forma periòdica cada any (LOPEZ, 1983; TOMAS, 1988).

Així doncs, es podria establir un gradient d'aigües que aniria des de les pràcticament dolces i oligohalines, fins a les hipersalines o marines, passant per un ampli ventall de mesohalines. Paral-lelament a aquestes variacions, també podem trobar tota una sèrie de grups d'espècies que apareixen amb una constància molt marcada en cada una de les condicions abans esmentades.

En total s'han identificat 161 tàxons, distribuïts en 23 cianoficies, 5 rodoficies, 2 euglenoficies, 1 criptoficia, 1 crisofícia, 2 craspedoficies, 86 bacil-larioficies, 3 tribofícies, 36 cloroficies i 2 zignematoficies.

A continuació presentem el catàleg florístic amb indicació del número de localitat on s'ha observat cada tàxon.

\section{Cyanophyceae}

Anabaena ambigua Anabaena oscillarioides Aphanocapsa littoralis 
Calothrix clavata

1,5

Chamaesiphon incrustans

4

Chroococcus minutus

1

Chroococcus turgidus

2,5

Coelosphaerium minutissimum

5

Dermocarpa clavata

Lyngbya aestuarii

1,5

Lyngbya epiphytica

1

Lyngbya halophila

$1,4,5,7$

Lyngbya hieronymusii

4,5

Lyngbya kützingii

5

Microchaete grisea

$1,4,5$

Oscillatoria nigroviridis

5

Oscillatoria okenii

1,5

Oscillatoria sancta

5

Oscillatoria tenuis

1

5

Spirulina labyrinthiformis

5

Synechococcus aeruginosus

4

Xenococcus kerneri

1

Xenococcus minimus

4,5

\section{Rhodophyceae}

Ceramium diaphanum

Chondria tenuissima

Compsopogon coeruleus

Polysiphonia denudata

Polysiphonia sertulariodes

\section{Euglenophyceae}

Lepocinclis salina

Trachelomonas volvocina

\section{Cryptophyceae}

Cryptomonas obovoidea

\section{Chrysophyceae}

Dinobryon petiolatum

\section{Craspedophyceae}

Salpingoeca pyxidium

1

Salpingoeca urceolata

\section{Bacillariophyceae}

Achnanthes affinis

Achnanthes brevipes v. intermedia

Achnanthes brevipes v. parvula

Achnanthes lanceolata

Achnanthes minutissima

4

$1,4,5,7$

1,5

4

4 
Amphora coffeaeformis

Amphora coffeaeformis v. acutiuscula

Amphora commutata

Amphora holsatica

Amphora lybica

Amphora ovalis

Amphora pediculus

Amphora perpusilla

Anomoeoneis sphaerophora

Bacillaria paradoxa

Cocconeis pediculus

Cocconeis placentula

Cyclotella meneghiniana

Cymbella cymbiformis

Cymbella cymbiformis v. nonpunctata

Cymbella minuta

Cymbella silesiaca

Diatoma tenue v. elongatum

Diploneis didyma

Entomoneis alata

Epithemia adnata

Epithemia turgida

Fragilaria capucina

Fragilaria construens v. subsalina

$1,4,5,7$

$1,4,5$

4

4

4,5

Fragilaria construens v. venter

4

4

5

Gomphonema angustum

Gomphonema gracile

Gomphonema olivaceum

Gomphonema parvulum

5

4,5

4

4,5

4

Gomphonema truncatum

4,5

Gyrosigma macrum

4,5

Mastogloia aquilegiae

5

Mastogloia elliptica

Mastogloia elliptica v. oblonga

Mastogloia grevillei

2

1

1

Mastogloia pumila

1

Melosira juergensii

$1,4,7$

Melosira varians

7

Navicula sp.

Navicula capitoradiata

4,5

1

4

Navicula cari

Navicula cincta

1

Navicula cryptocephala

4,5

Navicula cryptotenella

1,4

Navicula digitoradiata

$1,4,5,7$

Navicula gregaria

5

5

Navicula halophila

Navicula hungarica

$1,4,5$

Navicula lanceolata

Navicula menisculus

Navicula mutica v. lanceolata 
Navicula neoventricosa $\quad 5$

Navicula peregrina

Navicula pygmaea

Navicula radiosa

Navicula salinarum

Navicula subminuscula

Navicula veneta

Nitzschia amphibia

Nitzschia communis

Nitzschia denticuloides

Nitzschia elegantula

Nitzschia filiformis

Nitzschia frustulum

Nitzschia hungarica

Nitzschia inconspicua

Nitzschia intermedia

Nitzschia palea

Nitzschia scalpelliformis

Pleurosigma elongatum

Rhoicosphenia abbreviata

Rhopalodia gibberula

Rhopalodia gibberula v. vanheurkii

Rhopalodia musculus

Stauroneis salina

Stephanodiscus astraea v. minutula

Surirella minuta

Synedra pulchella

Synedra tabulata

Synedra ulna

Thalassiosira weissflogii

\section{Tribophyceae}

Tribonema affine

Tribonema elegans

Tribonema vulgare

\section{Chlorophyceae s.l.}

Aphanochaete pascheri

Aphanochaete repens

Characium ensiforme

Chlamydomonas inaequalis

Chlorella homosphaera

Cladophora glomerata v. crassior

Crucigenia tetrapedia

Enteromorpha flexuosa

Enteromorpha intestinalis

Enteromorpha prolifera

$$
\begin{aligned}
& 1,4,5,7 \\
& 5 \\
& 4 \\
& 4 \\
& 1,2,4,5 \\
& 4 \\
& 1 \\
& 4 \\
& 5 \\
& 5 \\
& 1 \\
& 4
\end{aligned}
$$

Epibolium dermaticola Monoraphidium arcuatum Monoraphidium circinale 
Monostroma membranaceum $\quad 7$

Oedogonium capillare $\quad 6$

Oedogonium intermedium 4

Pediastrum simplex $\quad 5$

Pediastrum tetras $\quad 5$

Planctonema lauterbornii 3

Pseudotetraspora marina $\quad 1,4$

Rhizoclonium riparium 1,5

Scenedesmus acutus $\quad 5$

Scenedesmus ecornis 4

Scenedesmus obliquus $\quad 1$

Scenedesmus ovalternus v. graevenitzii 1

Scenedesmus protuberans $\quad 5$

Scenedesmus quadricauda $\quad 5$

Scenedesmus quadrispina 5

Sphaerellopsis gloeosphaera $\quad 5$

Sykidion droebakense $\quad 1$

Tetraedron minimum $\quad 4$

Tetraselmis arnoldii 1

$\begin{array}{ll}\text { Ulothrix pseudoflacca } & 1,5\end{array}$

Ulothrix subtilissima $\quad 3,4$

Ulothrix zonata 4

Uronema africanum 4,5

\section{Zygnematophyceae}

Closterium parvulum 4

Cosmarium botrytis $\quad 5$

En conjunt, la major part d'espècies es troben sobre les tiges de Phragmites australis, fet que relacionem amb la presència perllongada de les tiges d'aquest helòfit a dins de l'aigua, respecte la temporalitat dels hidròfits. Aquests apareixen de forma més efimera (una o dues estacions) $i$, per tant, les poblacions d'epifits que presenten no assoleixen mai l'alta diversitat observada a les tiges del canyís.

Les algues epifitiques multicel-lulars d'aigües oligohalines estan representades per elements del Cladophoretum fractae rhizoclonietosum, del Cladophoretum crassioris Margalef, 1983 (Syn.: Cladophoretum crispatae Margalef, 1944) i del Compsopogonetum coerulei Margalef, 1983, amb espècies com Aphanochaete repens, Cladophora sp. pl., Compsopogon coeruleus, Cosmarium botrytis, Lyngbya halophila, i Rhizoclonium riparium. En aigües mesohalines predominen les espècies de Enteromorpha i Monostroma, així com Lyngbya aestuarii i Spirulina labyrinthiformis. A les llacunes amb una marcada influència marina les espècies precedents són substituïdes per elements del Polysiphonieto-Chaetomorphetum Margalef, 1983, amb Ceramiun sp. pl., Chondria tenuissima i Polysiphonia denudata, espècies pròpies del mar.

Les diatomees manifesten una elevada sensibilitat ecològica pels canvis en la salinitat de l'aigua. Així doncs, a les llacunes costaneres, en existir una gran amplitud de variació en la concentració de clorurs, també hi trobarem una notable representació de diatomees (TomAS, 1988). Les comunitats descrites de diatomees en aquests medis són també molt variades $\mathrm{i}$ sovint presenten moltes espècies en comú, com ara els tàxons eurioics Amphora perpusilla, Bacillaria paradoxa, Cyclotella meneghiniana, Navicula cari, N. cryptocephala, N. gregaria, Nitzschia amphibia, N. frustulum, Rhoicosphenia abbreviata i Synedra ulna. En aigües més o 
menys dolces o molt oligohalines trobem espècies pròpies d'aigües continentals com $A c h$ nanthes minutissima, Cymbella cymbiformis, Gomphonema sp. pl. o Nitzschia denticuloides, que no presenta afinitats amb cap associació d'algues. En general, aquest conjunt d'espècies es troba rarament, i només pren importància en aquelles localitats on hi ha un aport important d'aigües dolces, que generalment provenen d'arrossars. El grup d'espècies que creix en aigües mesohalines és força variat i va des de les aigües poc salabroses (Synedrion tabulatae Margalef, 1951; Amphorion acutiusculae Margalef, 1951) fins a les talassohalines, dominades per Amphora tenerrima, Licmophora sp. pl. i Mastogloia pusilla (TOMAS, 1988).

\section{Bibliografía}

CAmbra, J. (1987). Observaciones sobre el perifiton de macrófitos en sistemas lacustres del NE. de España. Actas IV Congr. Esp. Limnologia: 105-114.

CAmbra, J. (1990a). Distribución de algas epifiticas en sistemas lacustres de Cataluña (NE. de España). (en prensa)

CAMBra, J. (1991a). Contribució al coneixement de les algues epifitiques en estanys dels Pirineus. Scientia Gerundensis, 17: 17-27

Cambra, J. (1991b). Contribució a l'estudi de les algues epifítiques dels estanys de Banyoles, Basturs i Estanya. Orsis, 6: 27-44

Comin, F. A. (1984). Características físico-químicas y fitoplancton de las lagunas costeras, Encañizada, Tancada y Buda (Delta del Ebro). Oecol. Aquat. 5:57-141.

LÓPEZ, P. (1982). Aguas salinas epicontinentales próximas a la costa mediterránea española. Tesi Doctoral. Univ. Barcelona. 221 pp.

LOPEZ, P.; ARMENGOL, J. \& F.A. COMin (1984). Varación de las características químicas en la laguna de la Massona. Limnética 1:1-8.

Margalef, R. (1944). Datos para la flora algológica de nuestras aguas dulces. Publ. Inst. Bot. Barcelona 4:1-120.

MARGalef, R. (1982). Limnologia. Ed. Omega. Barcelona. 1010 pp.

Riera, X.; Domínguez-Panella, A.; Polo, L.; Moreno-Amich, R. \& C. Abella (1985). Dinámica de la meromixis en la laguna costera de la Massona (Alt Empordà, Girona), ciclo anual e intrusiones marinas. Actas IV Congr. Esp. Limnologia: 33-44.

Tomas, X. (1988). Diatomeas de las aguas epicontinentales saladas del litoral mediterráneo de la península Ibérica. Tesi Doctoral. Univ. Barcelona. 485 pp. 